Brazilian Journal

of Chemical

\title{
EFFECTIVENESS-NTU COMPUTATION WITH A MATHEMATICAL MODEL FOR CROSS-FLOW HEAT EXCHANGERS
}

\author{
H. A. Navarro ${ }^{1 *}$ and L. C. Cabezas-Gómez ${ }^{2}$ \\ ${ }^{1}$ Departamento de Estatística, Matemática Aplicada e Computação, IGCE, UNESP, \\ Av. 24-A, 1515 Cx.P 178, CEP: 13506-700, Rio Claro - SP, Brazil. \\ E-mail: helio@rc.unesp.br \\ ${ }^{2}$ Departamento de Engenharia Mecânica, Escola de Engenharia de São Carlos, USP, \\ Av. Trabalhador São-carlense 400, CEP: 13566-590, Centro, São Carlos - SP, Brazil. \\ E-mail: lubencg@sc.usp.br
}

(Received: June 14, 2005 ; Accepted: October 11, 2006)

\begin{abstract}
Due to the wide range of design possibilities, simple manufactured, low maintenance and low cost, cross-flow heat exchangers are extensively used in the petroleum, petrochemical, air conditioning, food storage, and others industries. In this paper a mathematical model for cross-flow heat exchangers with complex flow arrangements for determining $\varepsilon$-NTU relations is presented. The model is based on the tube element approach, according to which the heat exchanger outlet temperatures are obtained by discretizing the coil along the tube fluid path. In each cross section of the element, tube-side fluid temperature is assumed to be constant because the heat capacity rate ratio $\mathrm{C}^{*}=\mathrm{C}_{\min } / \mathrm{C}_{\max }$ tends toward zero in the element. Thus temperature is controlled by effectiveness of a local element corresponding to an evaporator or a condensertype element. The model is validated through comparison with theoretical algebraic relations for single-pass cross-flow arrangements with one or more rows. Very small relative errors are obtained showing the accuracy of the present model. $\varepsilon$-NTU curves for several complex circuit arrangements are presented. The model developed represents a useful research tool for theoretical and experimental studies on heat exchangers performance.

Keywords: Effectiveness; NTU; Heat exchangers; Mathematical model.
\end{abstract}

\section{INTRODUCTION}

For calculation of heat exchanger performance, if only the inlet temperatures are known, it is preferable to use the effectiveness-number of transfer units ( $\varepsilon$-NTU) method, which simplifies the algebra involved in predicting the performance of complex flow arrangements. $\varepsilon$-NTU relations in algebraic form are useful in computational calculations for design and experimental studies. For compact heat exchangers the mechanism of heat transfer and pressure drop is fairly complex, and as a result, analytical derivation of $\varepsilon$-NTU relations is a difficult task. It should be emphasized that the use of correct $\varepsilon$-NTU relations should be carefully considered before applying the appropriate heat transfer correlation to sizing or rating a heat exchanger.

Several models of plate-fin and tube heat exchangers have been published in the literature. For this kind of heat exchanger, air is commonly passed between the fin plates. Domanski (1991) presented a discretization model based on a tube-by-tube approach. Each tube with associated fins works as a heat exchanger. Bensafi et al. (1997) proposed a model that discretizes heat exchangers into tube elements. Local values of properties and heat transfer

*To whom correspondence should be addressed 
coefficients are used. The authors also present a computational procedure, which requires data on the coil geometry and circuit and operational parameters such as temperature, mass flow rate, and pressure. In this model, the cooling coils were analyzed by a log mean temperature difference method. Vardhan and Dhar (1998) proposed a model that discretizes the coil into nodes along the tube-side path and carries out repetitive movement between the tube element entrance and exit, while simultaneously updating the values of the air stream properties. Each element uses an effectiveness computed by mixed-unmixed cross-flow $\varepsilon$-NTU relations (Kays and London, 1998) with the air side characterized by the minimum heat capacity rate. Corberán and Melón (1998) developed a model discretizing the tube path with a UA-log mean temperature difference local approach to test the $\mathrm{R} 134 \mathrm{a}$ evaporation and condensation correlation. A comparison of simulated with experimental data shows the most appropriate correlation for computational simulation. Using a similar discretization model based on the $\varepsilon$-NTU method, Bansal and Purkayastha (1998) simulated the performance of alternative refrigerants in heat exchangers of vapor compression refrigeration/heat pump systems.

This study presents a mathematical model for determining $\varepsilon$-NTU relations for cross-flow heat exchangers with complex flow arrangements. This methodology was recently published by Navarro and Cabezas-Gomez (2005) and it is presented here in more detail. The model is based on the tube element approach, according to which the heat exchanger outlet temperatures are obtained by discretizing the coil along the tube fluid path. Each element is composed of a piece of tube with its fins. The size of the element is sufficiently small for the heat capacity rate ratio of the external fluid to be small. In the cross section of the element, the heat capacities rate ratio $\mathrm{C}^{*}=\mathrm{C}_{\min } / \mathrm{C}_{\max }$ tends to zero and the tube-side fluid temperature is assumed to be constant. Thus the temperature in the element is controlled by a local effectiveness corresponding to that where one of the fluids changes phase (constant temperature). Section 2 describes the proposed model, numerical discretization and algorithms for computing effectiveness. A theoretical comparison between the model and algebraic relations is carried out in section 3. $\varepsilon$-NTU values for the cross-flow heat exchanger for a few complex geometries are presented in section 4.

The present paper is based on the work of
Navarro and Cabezas-Gómez (2005), and introduces two new aspects. One consists in a more detailed explanation of the computational methodology (see section 2 and Table 1). This information allows a better understanding of how the numerical computations are performed. The other new aspect is related to the new results and discussion presented in section 4 . These results were obtained for complex heat exchanger geometries for which $\varepsilon$-NTU relations are not available. This analysis also shows how important it is to accurately compute the heat exchanger effectiveness so as not to incur large errors when determining the heat exchanger coefficient or during the heat exchanger rating procedure.

\section{DEVELOPMENT OF THE MATHEMATICAL MODEL}

\section{Definitions}

Effectiveness, $\varepsilon$, is defined as the ratio of the actual heat transfer rate for a heat exchanger to the maximum possible heat transfer rate, namely,

$$
\begin{aligned}
& \varepsilon=\frac{\mathrm{q}}{\mathrm{q}_{\max }}=\frac{\mathrm{C}_{\mathrm{h}}\left(\mathrm{T}_{\mathrm{h}, \mathrm{i}}-\mathrm{T}_{\mathrm{h}, \mathrm{o}}\right)}{\mathrm{C}_{\min }\left(\mathrm{T}_{\mathrm{h}, \mathrm{i}}-\mathrm{T}_{\mathrm{c}, \mathrm{i}}\right)}= \\
& \frac{\mathrm{C}_{\mathrm{c}}\left(\mathrm{T}_{\mathrm{c}, \mathrm{o}}-\mathrm{T}_{\mathrm{c}, \mathrm{i}}\right)}{\mathrm{C}_{\min }\left(\mathrm{T}_{\mathrm{h}, \mathrm{i}}-\mathrm{T}_{\mathrm{c}, \mathrm{i}}\right)}
\end{aligned}
$$

In general, it is possible to express effectiveness as a function of the number of transfer units, NTU; the heat capacity rate ratio, $\mathrm{C}^{*}$; and the flow arrangement in the heat exchanger,

$\varepsilon=\mathrm{f}\left(\mathrm{NTU}, \mathrm{C}^{*}\right.$, flow arrangement $)$

with the dimensionless number of transfer units (NTU) that is used for heat exchanger analysis and is defined as

$$
\mathrm{NTU}=\frac{\mathrm{UA}}{\mathrm{C}_{\min }}
$$

and the dimensionless heat capacity rate ratio

$$
\mathrm{C}^{*}=\frac{\mathrm{C}_{\min }}{\mathrm{C}_{\max }}
$$


where $\mathrm{C}_{\min } / \mathrm{C}_{\max }$ is equal to $\mathrm{C}_{\mathrm{c}} / \mathrm{C}_{\mathrm{h}}$ or $\mathrm{C}_{\mathrm{h}} / \mathrm{C}_{\mathrm{c}}$, depending on the relative magnitudes of the hot and cold fluid heat capacity rates.

\section{Governing Equations for the Cross-flow Heat Exchanger}

The governing equations presented in this section are developed for cross-flow heat exchangers with one fluid mixed and the other unmixed, in accordance with Kays and London (1998). Figure 1 shows the temperature variation for a single-pass cross-flow mixed-unmixed heat exchanger, i.e., heat exchanger with one row. In this case, it is assumed that the hot fluid is mixed (tube side) and the cold is unmixed. Nevertheless, the model that was developed for this case is also valid when the hot fluid is unmixed and the cold is mixed. For this condition the subscript hot and cold must be interchanged in all equations.

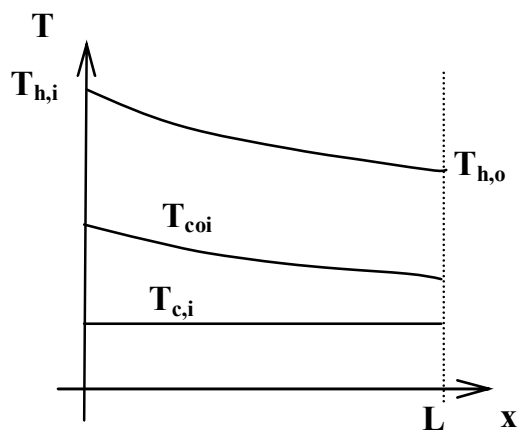

(a)

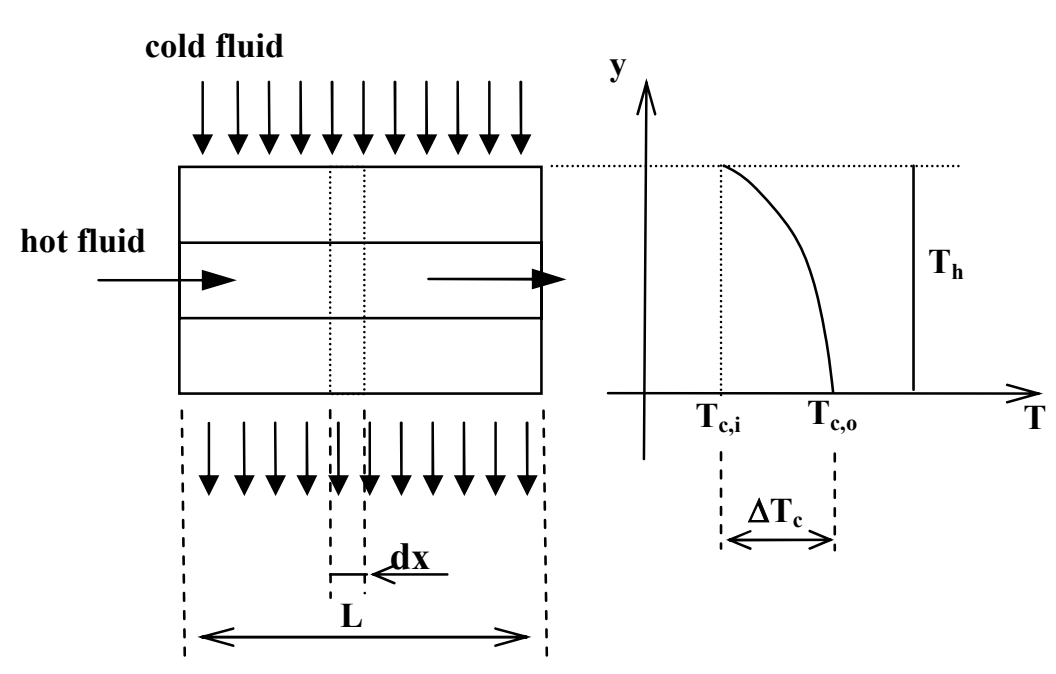

(b)

Figure 1: (a) Variations in air and fluid temperature in the longitudinal direction with respect to the fluid flow;

(b) Variation in cross-flow air temperature in a differential volume element of the heat exchanger.

Figure 1(a) illustrates the variations in hot and cold temperature along a tube of length $\mathrm{L}$, whereas Fig. 1(b) shows both temperature variations along the length cold fluid flow in the differential length $(\mathrm{dx})$. In this infinitesimal section, the cold mass flow rate is low and therefore the hot fluid temperature is constant. The energy balance for the differential length, $\mathrm{dx}$, for the hot and cold fluids can be written as

$$
\begin{aligned}
& \delta q=-C_{h} d_{h} \\
& \delta q=d_{c} \Delta T_{c}
\end{aligned}
$$

where $\Delta T_{c}=\left(T_{c, 0}-T_{c, i}\right)$ is the variation in temperature of the cold fluid for the differential length, $\mathrm{dx}$.

Using the fact that in the differential section, $\mathrm{dx}$, the cold mass flow rate is low and then that in this section the hot capacity rate, $C_{h}$, is constant, the differential heat capacity rate ratio is expressed as

$$
\mathrm{dC}^{*}=\frac{\mathrm{dC}_{\mathrm{c}}}{\mathrm{C}_{\mathrm{h}}} \rightarrow 0
$$

For an evaporator or condenser, $C^{*}=0$, because if one fluid remains at a constant temperature throughout the heat exchanger, its specific heat, and thus its capacity rate, is by definition equal to infinity. Under these conditions, the effectiveness relation reduces to $\varepsilon=1-\mathrm{e}^{-\mathrm{NTU}}$. So, for Eq. (5) and a given temperature (Fig.1b), a condenser-type of effectiveness expression is applicable. Then, using the effectiveness definition (Eq. 1), a parameter $\Gamma$ that expresses the 'local effectiveness' in the differential section $\mathrm{dx}$ can be written as (Kays and London, 1998)

$$
\Gamma=\frac{\Delta \mathrm{T}_{\mathrm{c}}}{\left(\mathrm{T}_{\mathrm{h}}-\mathrm{T}_{\mathrm{c}, \mathrm{i}}\right)}=1-\mathrm{e}^{-\frac{\mathrm{UdA}}{\mathrm{dC}_{\mathrm{c}}}}
$$


Assuming that both cold flow and heat transfer area A distributions are uniform, the following relations are valid

$$
\begin{aligned}
& \frac{\mathrm{dC}_{\mathrm{c}}}{\mathrm{dA}_{\mathrm{fr}}}=\frac{\mathrm{C}_{\mathrm{c}}}{\mathrm{A}_{\mathrm{fr}}}=\text { const } \\
& \frac{\mathrm{dC}_{\mathrm{c}}}{\mathrm{dA}}=\frac{\mathrm{C}_{\mathrm{c}}}{\mathrm{A}}
\end{aligned}
$$

Thus, along the tube length $\mathrm{L}$

$\Gamma=1-\mathrm{e}^{-\frac{\mathrm{UA}}{\mathrm{C}_{\mathrm{c}}}}=$ const

Combining equations (4.a), (4.b) and (6) and separating the variables results in

$$
\frac{\mathrm{dT}_{\mathrm{h}}}{\mathrm{T}_{\mathrm{h}}-\mathrm{T}_{\mathrm{c}, \mathrm{i}}}=-\Gamma \mathrm{dC}^{*}=-\Gamma \frac{\mathrm{C}_{\mathrm{c}}}{\mathrm{C}_{\mathrm{h}}} \frac{\mathrm{dA}_{\mathrm{fr}}}{\mathrm{A}_{\mathrm{fr}}}
$$

In Eq. (9) it should be noted that $C_{c}, C_{h}$, and $A_{f r}$ are the total magnitudes and are not variables. As mentioned previously, the above development is valid for a single-pass cross-flow heat exchanger with one fluid mixed and the other unmixed. For this kind of heat exchanger, the integration of Eq. (9) can easily be done analytically, obtaining the $\varepsilon$-NTU relations (see Eq. 14 later). Nevertheless, the majority of heat exchangers for engineering applications have a complex geometry with more than one row and several circuits. Therefore, application of the above procedure is not trivial. The derivation and integration of an equation such as Eq. (9) is difficult and results in a numerical procedure due to the nonvalidity of Eqs. (7b) and (8) for the overall heat exchanger area and to a variation in temperature distribution of the cold (unmixed) fluid,
$\mathrm{T}_{\mathrm{c}, \mathrm{i}}$, in each row of the heat exchanger.

\section{Numerical Model}

To solve this problem, a new simulation model based on the above procedure was developed. This new model consists in application of the previous equations to a control volume called the element, where these equations are valid because each element acts as a single-pass cross-flow heat exchanger with one fluid mixed and the other unmixed. These elements are obtained by breaking the heat exchanger into three-dimensional control volumes (Fig. 2). This type of discretization produces elements identified by the triplet $(\mathrm{i}, \mathrm{j}, \mathrm{k})$, where the indices $1 \leq \mathrm{i} \leq \mathrm{N}_{\mathrm{e}}, 1 \leq \mathrm{j} \leq \mathrm{N}_{\mathrm{t}}$, and $1 \leq \mathrm{k} \leq \mathrm{N}_{\mathrm{r}}$ represent the element on a particular tube, the tube, and the row, respectively. The distinguishing feature of the proposed model is that it performs an elementby-element iterative analysis, based on the application of the parameter $\Gamma$ (Eq. 8) for each element, thereby permitting simulation of cross-flow heat exchangers with different flow arrangements (one fluid mixed and the other unmixed, both mixed, and both unmixed) through the utilization of governing equations (section 2.2) that are valid for a simple cross-flow mixed/unmixed heat exchanger, i.e., for the element. Thus, the simulation methodology proposed in this paper must be divided into two parts. The first is the use of governing equations (section 2.2) for a small mixed/unmixed cross-flow heat exchanger (element) to obtain the simulation model, described in this section. The second is the utilization of this model for all elements through the proposed algorithm (section 2.4), to simulate the cross-flow heat exchanger with one fluid mixed and the other unmixed, both fluids mixed, or both fluids unmixed.

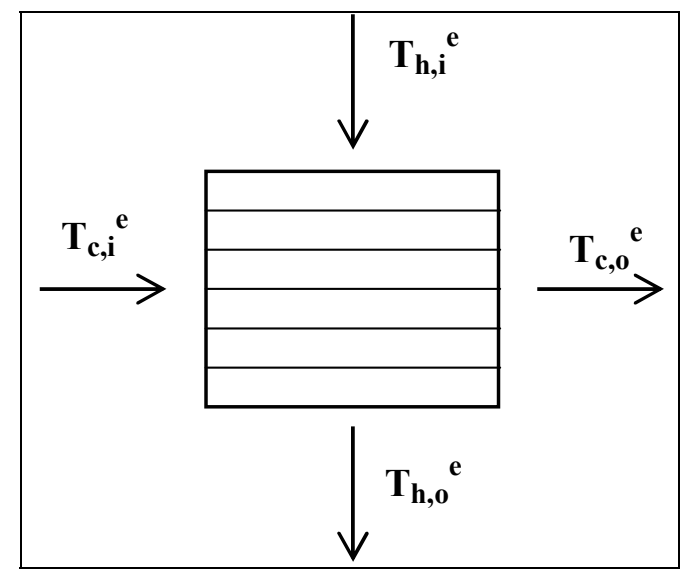

Figure 2: Element (i, j, k) with one fluid mixed and the other unmixed. 
Therefore, the proposed simulation model is based on integration of the governing equations described above (section 2.2), for which the elements or control volumes are considered small. This condition supports the validity of the simulation model developed. Thus, it is reasonable to assume that the hot mixed fluid temperature varies linearly in the control volume with an exponential variation for the cold unmixed fluid. The average hot element fluid temperature is expressed as

$$
\mathrm{T}_{\mathrm{h}}{ }^{\mathrm{e}}=0.5\left(\mathrm{~T}_{\mathrm{h}, \mathrm{i}}^{\mathrm{e}}+\mathrm{T}_{\mathrm{h}, \mathrm{o}}{ }^{\mathrm{e}}\right)
$$

where the superscript e is associated with a specific element $(i, j, k)$. Integration of Eq. (4a) in the element results in

$$
\mathrm{q}^{\mathrm{e}}=-\mathrm{C}_{\mathrm{h}}{ }^{\mathrm{e}}\left(\mathrm{T}_{\mathrm{h}, \mathrm{o}}{ }^{\mathrm{e}}-\mathrm{T}_{\mathrm{h}, \mathrm{i}}{ }^{\mathrm{e}}\right)
$$

From the heat balance for the cold fluid, through integration of Eq. (4b), and using Eq. (7a), the following expression can be obtained:

$$
\mathrm{q}^{\mathrm{e}}=\Delta \mathrm{T}_{\mathrm{c}}^{\mathrm{e}} \int_{\mathrm{e}} \mathrm{dC}_{\mathrm{c}}=\Delta \mathrm{T}_{\mathrm{c}}^{\mathrm{e}} \int_{\mathrm{e}} \frac{\mathrm{C}_{\mathrm{c}}}{\mathrm{A}_{\mathrm{fr}}} \mathrm{dA}_{\mathrm{fr}}=\Delta \mathrm{T}_{\mathrm{c}}^{\mathrm{e}} \mathrm{C}_{\mathrm{c}}^{\mathrm{e}}
$$

where $\Delta \mathrm{T}_{\mathrm{c}}{ }^{\mathrm{e}}=\mathrm{T}_{\mathrm{c}, \mathrm{o}}{ }^{\mathrm{e}}-\mathrm{T}_{\mathrm{c}, \mathrm{i}}{ }^{\mathrm{e}}$ represents the variation in cold fluid temperature in the element. The algebraic equation system is closed by integration of Eq. (6) into the element that results in

$$
\Gamma^{\mathrm{e}}=\frac{\Delta \mathrm{T}_{\mathrm{c}}^{\mathrm{e}}}{\left(\mathrm{T}_{\mathrm{h}}^{\mathrm{e}}-\mathrm{T}_{\mathrm{c}, \mathrm{i}}^{\mathrm{e}}\right)}=1-\mathrm{e}^{-\frac{(\mathrm{UA})^{\mathrm{e}}}{\mathrm{C}_{\mathrm{c}}^{\mathrm{e}}}}
$$

The last term of Eq. (13) is equal to Eq. (8) for a single-pass cross-flow heat exchanger, but it is different for another kind of cross-flow heat exchanger because for complex flow arrangements the analytical integration of the last term in Eq. (6), which results in Eq. (8), is no longer possible because we cannot assume Eq. (7b), i.e., a uniform heat transfer area A distribution. Equations (10) to (13) represent the simulation model developed in this work, consisting in a closed system of five equations and five unknowns for each element, i. e., $\mathrm{q}^{\mathrm{e}}, \Gamma^{\mathrm{e}}, \mathrm{T}_{\mathrm{h}}{ }^{\mathrm{e}}$, $T_{h, o}{ }^{e}$, and $\Delta T_{c}{ }^{e}$, for the following given parameters $\mathrm{T}_{\mathrm{h}, \mathrm{i}}{ }^{\mathrm{e}}, \mathrm{T}_{\mathrm{c}, \mathrm{i}}{ }^{\mathrm{e}},(\mathrm{UA})^{\mathrm{e}}, \mathrm{C}_{\mathrm{c}}{ }^{\mathrm{e}}$, and $\mathrm{C}_{\mathrm{h}}{ }^{\mathrm{e}}$. To solve this system for the heat exchanger an iterative procedure is needed. An algorithm for this process is presented in the following section.

\section{Algorithm for the Computation of Effectiveness}

The proposed model can be used to simulate simple and complex geometries involving multi-pass parallel and counter cross-flow heat exchangers with several circuit arrangement configurations. The procedure allows computation of various parameters like $\varepsilon$-NTU relations, mean-temperature difference, cold and hot fluid temperature distributions, heat transfer area, and friction and heat transfer coefficients. Nevertheless, this work will be related mainly to the obtainment of $\varepsilon$-NTU graphs for several cross-flow heat exchanger arrangements. For derivation of the model it is assumed that the heat exchanger and the tube curves are adiabatic, the mixed fluid inlet conditions are homogenous for each element, and the unmixed fluid is uniformly distributed.

To obtain the $\varepsilon$-NTU relations, the computational algorithms shown in Table 1 were developed. These algorithms assume that the hot fluid is mixed and the cold is unmixed. Nevertheless, it is also valid when the hot fluid is unmixed and the cold is mixed, as previously assumed. In this case the subscripts (hot and cold) are interchanged in all referenced equations of the algorithms.

Table 1 shows the algorithm for calculation of effectiveness, $\varepsilon$. The first step consists in loading geometric data for a specific heat exchanger. This data file contains the necessary information, like the number of rows, tubes, and circuits and the flow arrangement for the mixed fluid. The algorithm inputs (steps 1.2 and 1.3) are NTU, $C^{*}$, and $C_{\min }=\left(C_{c}\right.$ or $\mathrm{C}_{\mathrm{h}}$ ). Effectiveness, $\varepsilon$, is the algorithm output and it is computed in step 1.8. It can be observed that the $\mathrm{T}_{\mathrm{c}, \mathrm{i}}, \mathrm{T}_{\mathrm{h}, \mathrm{i} \text {, }}$ and UA values, introduced in 1.4, are arbitrarily chosen for simulation purposes, since $\varepsilon$ depends solely on NTU, $\mathrm{C}^{*}$, and flow arrangement. The $(\mathrm{UA})^{\mathrm{e}}, \mathrm{C}_{\mathrm{c}}{ }^{\mathrm{e}}$, and $\mathrm{C}_{\mathrm{h}}{ }^{\mathrm{e}}$ values are calculated in 1.5 and 1.6, and they are used to calculate the parameter $\Gamma^{\mathrm{e}}$ for each element, using to Eq. (13). It should be noted that the procedure presented here (step 1.6) is valid only when the unmixed heat fluid capacity is at a minimum in the element, i.e., $\mathrm{C}_{\text {unmixed }}^{\mathrm{e}} / \mathrm{C}_{\text {mixed }}^{\mathrm{e}} \leq 1$. The number of elements in the discretization process, $\mathrm{N}_{\mathrm{e}}$, is calculated based on this relation. This means that for the minimum heat capacity rate of the heat exchanger $\mathrm{C}_{\min }=\mathrm{C}_{\text {unmixed, }}$, there is no restriction for the $\mathrm{N}_{\mathrm{e}}$ value, but when $\mathrm{C}_{\text {min }}=\mathrm{C}_{\text {mixed, }}$, the value $\mathrm{N}_{\mathrm{e}}$ should be large enough to guarantee the validity of the above relation. In step 1.7 , the heat exchanger temperature distribution is calculated iteratively and the convergence criterion is related to the cold fluid outlet temperature $\left(T_{c, 0}\right)$. Nevertheless the same 
convergence criterion can be related to the heat transfer rate $\mathrm{q}$ (step 1.8). This criterion is also checked in the computational program developed.

It should be noted that in step 1.7 the real temperature distribution is not computed. For this reason the parameter $\Gamma^{\mathrm{e}}$ is constant for all elements of the heat exchanger. In the case be considered computation of the real temperature distribution, the parameters $\Gamma^{\mathrm{e}}$ as well as $(\mathrm{UA})^{\mathrm{e}}, \mathrm{C}_{\mathrm{h}}{ }^{\mathrm{e}}$, and $\mathrm{C}_{\mathrm{c}}{ }^{\mathrm{e}}$, must be calculated for each element using local properties and heat transfer coefficients. For both cases, the cold and hot temperatures in each element are computed using the model proposed (Eqs. 10 through 13), and these values are used to update the inlet temperatures for the next element of the flow circuit. This update procedure depends on the geometry and is done for each circuit involving all its elements. It is the procedure that permits simulation of several types of cross-flow heat exchangers, i.e., with one fluid mixed and the other unmixed, both fluids mixed, or both unmixed.

Table 1: Algorithm for computation of effectiveness.

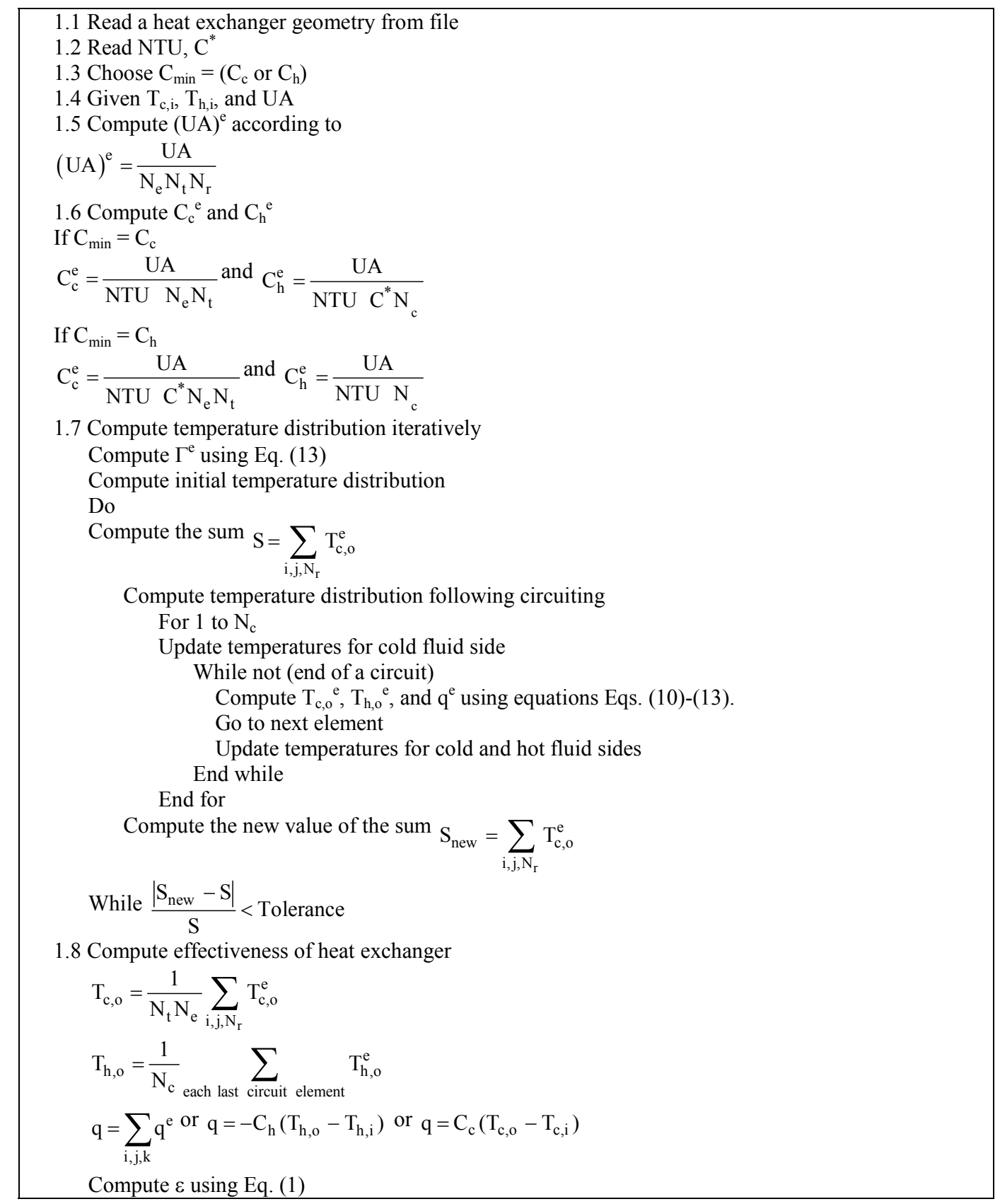




\section{THEORETICAL ANALYSIS OF THE MATHEMATICAL MODEL FOR CROSS- FLOW HEAT EXCHANGERS}

In this section a theoretical analysis of the validation of the proposed model is presented through a comparison between theoretical $\varepsilon$-NTU relations for single-pass cross-flow heat exchangers (Table 2 - ESDU, 1991; Incropera and DeWitt, 1996; Kays and London, 1998) and the same geometries with $\mathrm{N}_{\mathrm{t}}=1$ and $\mathrm{N}_{\mathrm{r}}=1,2,3,4,5,6,7,8,9,10,20,50$ saved in a database and designated as $\mathrm{t} 1, \mathrm{t} 2, \ldots \mathrm{t} 50$, respectively.

Table 2 shows the $\varepsilon$-NTU relations for a singlepass cross-flow arrangement and different numbers of tube rows. For a number of tube rows greater than four, the use of the approximate relation described by Eq. (18), which is assumed to be valid up to an infinite number of tube rows, $\mathrm{N}_{\mathrm{r}}=\infty$, is suggested in the literature (ESDU). Another, more accurate solution, which is valid only for $\mathrm{N}_{\mathrm{r}}=\infty$, is the infinite series solution taken from Stevens et al. (1957) and shown in Table 2 (Eq. 19). Thus, validation will be performed in two steps. First the simulation results are compared with theoretical analytical relations for one to four row configurations. Then the simulation results are compared with the solution of Eq. (19) for an infinite number of tube rows. Finally comments on the use and applicability of the approximate solution of Eq. (18) are presented. The main reason for this comparison is to show the accuracy of the proposed mathematical model. Thus, comparison with the infinite row solutions (approximation and series solution) is very important because several heat exchangers used by industry have more than four rows and it is difficult to obtain theoretical $\varepsilon$-NTU relations for this number of tube rows.

Table 2: Equations for the thermal effectiveness of the heat exchanger, $\varepsilon$, for single-pass cross-flow heat exchanger configurations with one or more rows

(Eqs. 14-18, see ESDU, 1991; Eq. 19, see Stevens, 1957).

\begin{tabular}{|c|c|c|c|}
\hline$N_{r}$ & Side of $\mathrm{C}_{\min }$ & Relation & Equation \\
\hline 1 & $\begin{array}{l}\text { Air } \\
\text { Tube fluid }\end{array}$ & $\begin{array}{l}\varepsilon=\frac{1}{\mathrm{C}^{*}}\left[1-\mathrm{e}^{-\mathrm{C}^{*}\left(1-\mathrm{e}^{-\mathrm{NTU}}\right)}\right] \\
\varepsilon=1-\mathrm{e}^{-\left(1-\mathrm{e}^{\mathrm{NTU} \mathrm{C}^{*}}\right) / \mathrm{C}^{*}}\end{array}$ & $\begin{array}{l}(14 a) \\
(14 b)\end{array}$ \\
\hline 2 & Air & $\begin{aligned} \varepsilon= & \frac{1}{\mathrm{C}^{*}}\left[1-\mathrm{e}^{-2 \mathrm{KC}^{*}}\left(1+\mathrm{C}^{*} \mathrm{~K}^{2}\right)\right] \\
\mathrm{K} & =1-\mathrm{e}^{-\mathrm{NTU} / 2} \\
\varepsilon & =1-\mathrm{e}^{-2 \mathrm{~K} / \mathrm{C}^{*}}\left(1+\frac{\mathrm{K}^{2}}{\mathrm{C}^{*}}\right) \\
\mathrm{K} & =1-\mathrm{e}^{-\mathrm{NTU} \mathrm{C}^{*} / 2}\end{aligned}$ & (15a) \\
\hline 3 & Air & $\begin{array}{l}\varepsilon=\frac{1}{C^{*}}\left[1-\mathrm{e}^{-3 \mathrm{KC}^{*}}\left(1+\mathrm{C}^{*} \mathrm{~K}^{2}(3-\mathrm{K})+\frac{3\left(\mathrm{C}^{*}\right)^{2} \mathrm{~K}^{4}}{2}\right)\right] \\
\mathrm{K}=1-\mathrm{e}^{-\mathrm{NTU} / 3} \\
\varepsilon=1-\mathrm{e}^{-3 \mathrm{~K} / \mathrm{C}^{*}}\left(1+\frac{\mathrm{K}^{2}(3-\mathrm{K})}{\mathrm{C}^{*}}+\frac{3 \mathrm{~K}^{4}}{2\left(\mathrm{C}^{*}\right)^{2}}\right) \\
\mathrm{K}=1-\mathrm{e}^{-\mathrm{NTU} \mathrm{C}^{*} / 3}\end{array}$ & (16a) \\
\hline 4 & Air & $\begin{array}{l}\varepsilon=\frac{1}{C^{*}}\left[1-\mathrm{e}^{-4 \mathrm{KC}^{*}}\left(1+\mathrm{C}^{*} \mathrm{~K}^{2}\left(6-4 \mathrm{~K}+\mathrm{K}^{2}\right)+4\left(\mathrm{C}^{*}\right)^{2} \mathrm{~K}^{4}(2-\mathrm{K})+\frac{8\left(\mathrm{C}^{*}\right)^{3} \mathrm{~K}^{6}}{3}\right)\right. \\
\mathrm{K}=1-\mathrm{e}^{-\mathrm{NTU} / 4} \\
\varepsilon=1-\mathrm{e}^{-4 \mathrm{~K} / \mathrm{C}^{*}}\left(1+\frac{\mathrm{K}^{2}\left(6-4 \mathrm{~K}+\mathrm{K}^{2}\right)}{\mathrm{C}^{*}}+\frac{4 \mathrm{~K}^{4}(2-\mathrm{K})}{\left(\mathrm{C}^{*}\right)^{2}}+\frac{8 \mathrm{~K}^{6}}{3\left(\mathrm{C}^{*}\right)^{3}}\right) \\
\mathrm{K}=1-\mathrm{e}^{-\mathrm{NTU} \mathrm{C}^{*} / 4}\end{array}$ & $(17 b)$ \\
\hline$\infty$ & & $\varepsilon=1-\mathrm{e}^{\left[\mathrm{NTU}^{0.22}\left(\mathrm{e}^{-\mathrm{C}^{*} \mathrm{NTU}^{0.78}}-1\right) / \mathrm{C}^{*}\right]}$ & (18) \\
\hline$\infty$ & & $\varepsilon=\frac{1}{\mathrm{C}^{*} \mathrm{NTU}} \sum_{\mathrm{n}=0}^{\infty}\left\{\left[1-\mathrm{e}^{-\mathrm{NTU}} \sum_{\mathrm{m}=0}^{\mathrm{n}} \frac{(\mathrm{NTU})^{\mathrm{m}}}{\mathrm{m} !}\right]\left[1-\mathrm{e}^{-\mathrm{C}^{*} \mathrm{NTU}} \sum_{\mathrm{m}=0}^{\mathrm{n}} \frac{\left(\mathrm{C}^{*} \mathrm{NTU}\right)^{\mathrm{m}}}{\mathrm{m} !}\right]\right\}$ & (19) \\
\hline
\end{tabular}


In Table 3 the maximum value of the relative error in the effectiveness values (theoretical $\varepsilon_{t}-$ Eqs. 14-17 versus simulated $-\varepsilon_{\mathrm{s}}$ ) for heat exchangers with different numbers of tube rows $\left(\mathrm{N}_{\mathrm{r}}=1,2,3,4\right)$ is shown. A maximum value of effectiveness is obtained using 1111 values of effectiveness $\varepsilon_{\mathrm{i}}\left(\mathrm{C}_{\mathrm{i}}{ }^{*}, \mathrm{NTU}_{\mathrm{i}}\right)$ where $0 \leq \mathrm{C}_{\mathrm{i}}{ }^{*} \leq 1$ and $0 \leq \mathrm{NTU}_{\mathrm{i}} \leq 10$ with 0.1 increments, respectively. The number of elements is calculated according to the criterion discussed in section 2.4 $\left(\mathrm{C}_{\text {unmixed }}^{\mathrm{e}} / \mathrm{C}_{\text {mixed }}^{\mathrm{e}} \leq 1\right)$. Results show that for $\mathrm{N}_{\mathrm{r}} \leq$ 4 , the maximum error is very small in all cases, indicating a perfect agreement between theoretical and simulated values.

For $\mathrm{N}_{\mathrm{r}}=\infty$, the simulation results for geometries $\mathrm{t} 5, \mathrm{t} 6, \mathrm{t} 7, \mathrm{t} 8, \mathrm{t} 9, \mathrm{t} 10, \mathrm{t} 20$, and $\mathrm{t} 50$ are compared with the theoretical infinite series solution for the unmixed/unmixed cross-flow arrangement (Stevens et al., 1957) (Eq. 19). The comparison is shown in Table 4, assuming again 1111 points. How well the present approach converges to the infinite series solution when $\mathrm{N}_{\mathrm{r}} \rightarrow \infty$ can be seen. With an increase in the number of tube rows, the simulation solution tends toward the theoretical value.

Table 3: Maximum relative error as a function of the number of tube rows between simulation results and theoretical relations for geometries $t 1, t 2, t 3$, and $t 4$.

\begin{tabular}{|c|c|c|c|}
\hline & & \multicolumn{2}{|c|}{ Maximum value of the relative error* $(\%)$} \\
\hline $\mathbf{N}_{\mathbf{r}}$ & Geometry & $\mathbf{C}_{\min }=\mathbf{C}_{\text {air }}$ & $\mathbf{C}_{\min }=\mathbf{C}_{\mathbf{t}}$ \\
\hline 1 & t1-Eq.(14) & $1.07 \times 10^{-6}$ & $1.44 \times 10^{-6}$ \\
2 & t2-Eq.(15) & $1.15 \times 10^{-6}$ & $1.55 \times 10^{-6}$ \\
3 & t3-Eq.(16) & $1.20 \times 10^{-6}$ & $1.61 \times 10^{-6}$ \\
4 & t4-Eq.(17) & $1.21 \times 10^{-6}$ & $1.65 \times 10^{-6}$ \\
\hline
\end{tabular}

*Relative error $=\frac{\left|\varepsilon_{\mathrm{s}}-\varepsilon_{\mathrm{t}}\right|}{\varepsilon_{\mathrm{t}}} 100$

Table 4: Comparison between model prediction and approximate infinite series solution.

\begin{tabular}{|c|c|c|c|}
\hline & & \multicolumn{2}{|c|}{$\begin{array}{c}\text { Model prediction versus infinite series solution (Eq. 19) } \\
\text { Average relative error (\%) }\end{array}$} \\
\hline $\mathbf{N}_{\mathbf{r}}$ & Geometry & $\mathbf{C}_{\min }=\mathbf{C}_{\text {air }}$ & $\mathbf{C}_{\min }=\mathbf{C}_{\mathbf{t}}$ \\
\hline & & $0 \leq \mathrm{NTU} \leq 10$ & $0 \leq \mathrm{NTU} \leq 10$ \\
5 & t5-Eq.(19) & $0.63,2.89$ & $0.45,2.89$ \\
6 & t6-Eq.(19) & $0.44,2.08$ & $0.32,2.08$ \\
7 & t7-Eq.(19) & $0.33,1.56$ & $0.24,1.56$ \\
8 & t8-Eq.(19) & $0.25,1.22$ & $0.18,1.22$ \\
9 & t9-Eq.(19) & $0.20,0.97$ & $0.14,0.97$ \\
10 & t10 - Eq.(19) & $0.16,0.79$ & $0.12,0.79$ \\
20 & t20 - Eq.(19) & $0.041,0.20$ & $0.029,0.20$ \\
50 & t50-Eq.(19) & $0.0066,0.033$ & $0.0047,0.033$ \\
\hline
\end{tabular}

*Average relative error $=\frac{1}{\mathrm{~N}} \sum_{1}^{\mathrm{N}} \frac{\left|\varepsilon_{\mathrm{s}}-\varepsilon_{\mathrm{t}}\right|}{\varepsilon_{\mathrm{t}}} 100$

Comparing the approximate infinite relation (Eq. 18) with the infinite series solution (Eq. 19) over 600 points $\left(0.1 \leq \mathrm{C}_{\mathrm{i}}{ }^{*} \leq 1\right.$ and $0.1 \leq \mathrm{NTU}_{\mathrm{i}} \leq 6$ with 0.1 increments), it is seen that the maximum relative error is $3.78 \%$ for $\mathrm{C}^{*}=1$ and NTU $=0.3$ and the average relative error is $0.683 \%$. For experimental determination of the heat transfer coefficient using the effectiveness-NTU reduction method, these errors are important. As it is difficult to derive algebraic relations for the interval $\mathrm{N}_{\mathrm{r}}=5$ to $\infty$, the approximate infinite relation (Eq. 18) is extensively used in industry and research laboratories. Even so, the proposed computational procedure allows results to be obtained with more precision, enhancing the research capabilities for determination of the convective heat transfer coefficient, mainly for those geometries and flow arrangements without available $\varepsilon$-NTU relations.

\section{$\varepsilon$-NTU GRAPHS FOR CROSS-FLOW HEAT EXCHANGERS WITH COMPLEX GEOMETRIES}

In the previous section results produced by the single-pass cross-flow heat exchanger were shown. For this kind of heat exchanger there are various theoretical relations and an approximate correlation for an infinite number of tube rows that can be used for rating and performance prediction purposes. 
Nevertheless, the majority of heat exchangers have other more complex configurations with many different flow arrangements. In these cases the availability of $\varepsilon$-NTU data is very useful for predicting heat exchanger performance. In this section an analysis of the elaboration of the $\varepsilon-\mathrm{NTU}$ graphs obtained with the present simulation program for different heat exchangers will be presented.

Recently, several projects to study and determine overall compact heat exchanger thermal performance have been developed (for example Wang et al., 1999a,b; Jang et al., 1998, among others). In these studies the $\varepsilon$-NTU theoretical relations shown in Table 2 for single-pass cross-flow heat exchangers with one or more rows are frequently used for experimental data reduction. Nevertheless, the appropriate $\varepsilon$-NTU equation to be used depends on the number of tube rows and the fluid side circuits (Wang et al., 2000). When different flow arrangements are used, such as Z, DX, and other multipass counter cross-flow heat exchanger configurations, errors will be made in data reduction using relations from Table 2. Next the errors involved in reducing the experimental data are shown assuming only the relations from Table 2 for computation of the effectiveness of other kinds of flow arrangements.

The tube circuit of the cross-flow heat exchangers analyzed is shown in Figure 3. The first configuration, Figure 3.a, is a Z-shaped crossflow, $\mathrm{N}_{\mathrm{t}}=12$ (geometry 1 ); the second, Figure 3.b, is a staggered two-row and two-circuit arrangement, $\mathrm{N}_{\mathrm{t}}=10$ (geometry 2); the third, Figure 3.c, is a staggered three-row and twocircuit arrangement, $\mathrm{N}_{\mathrm{t}}=10$ (geometry 3); and the fourth, Figure 3.d, is a staggered six-row and fivecircuit arrangement, $\mathrm{N}_{\mathrm{t}}=10$ (geometry 4). These four configurations were chosen to show the differences between the $\varepsilon$-NTU values obtained with the proposed model and the theoretical ones. Geometries 2 to 4 were taken from Rich (1973). (a)

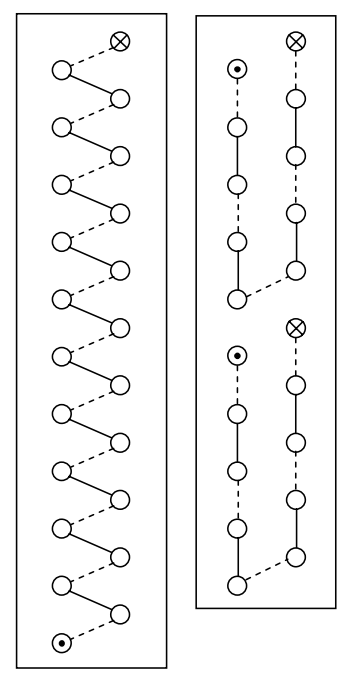

(c)

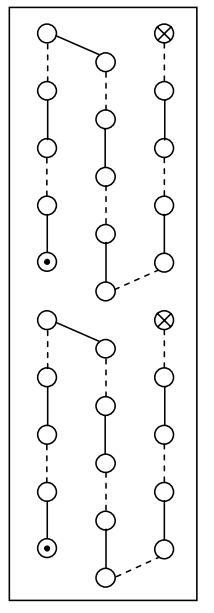

(d)

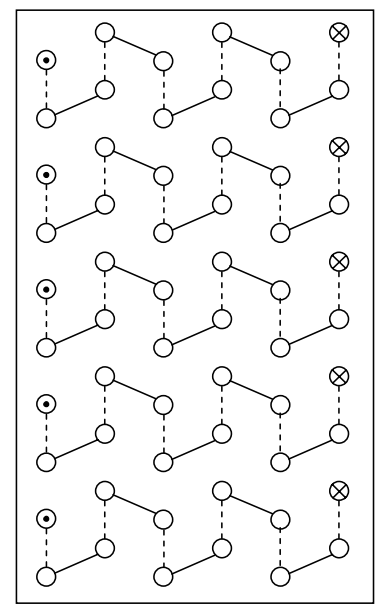

Figure 3: Scheme of the circuit arrangement for the cross-flow heat exchangers considered in the present study: (a) Z-shaped arrangement; (b) staggered two-row and two-circuit arrangement; (c) staggered three-row and twocircuit arrangement; (d) staggered six-row and five-circuit arrangement.

The effectiveness of the heat exchangers shown in Fig. 3 (a-d) is illustrated in Figs. 4-7. The heat capacity ratio varies from 0 to 1 with 0.25 increments. For $\mathrm{C}^{*}=0$, the equation $\varepsilon=1-\exp (-\mathrm{NTU})$ is used. These graphs were obtained with the computational program (see straight lines in Figs. 47). Observing Figs. 4 and 5, some differences due to the effect of the flow arrangement can be observed for the two-row heat exchangers. The two-row heat exchanger, geometry 2 flow arrangement, seems to have a better performance than the geometry 1 configuration. This effect is captured well by the program developed. With the theoretical relation for two rows (see Table 2), which is used in these two cases, the above effect of flow arrangement on $\varepsilon$ NTU behavior cannot be observed. This illustrates two important facts: first, the flow arrangement exerts a big influence over the $\varepsilon$-NTU values, and second, the use of a specific theoretical relation can introduce errors into the experimental results. 


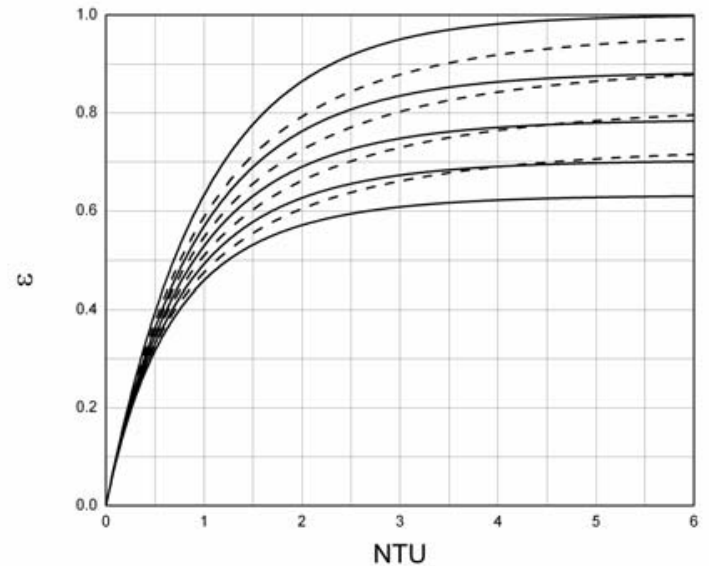

(a)

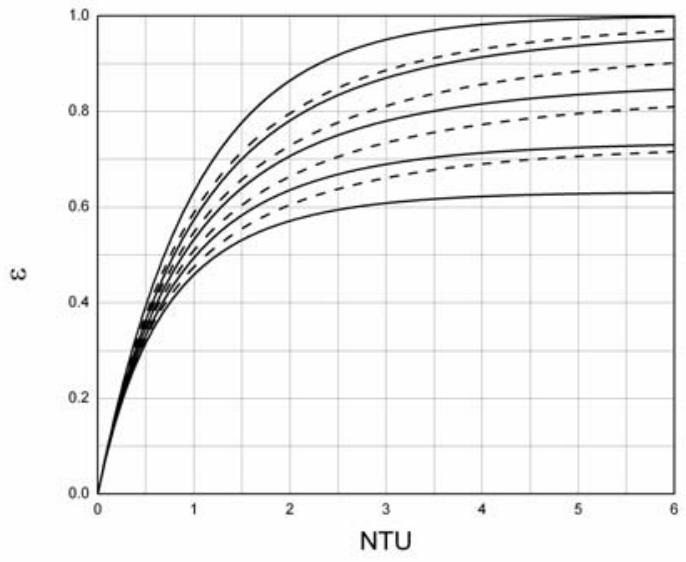

(b)

Figure 4: Effectiveness of the theoretical relation (dashed line) and the model prediction (straight line) of a Z-shaped cross-flow heat exchanger (geometry 1): (a) $\mathrm{C}_{\max }$ (mixed), $\mathrm{C}_{\min }$ (unmixed);

(b) $\mathrm{C}_{\min }$ (mixed), $\mathrm{C}_{\max }$ (unmixed).

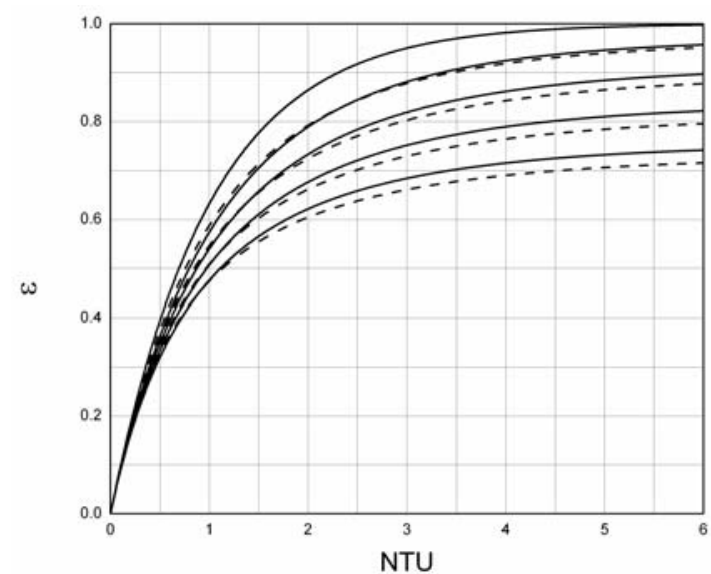

(a)

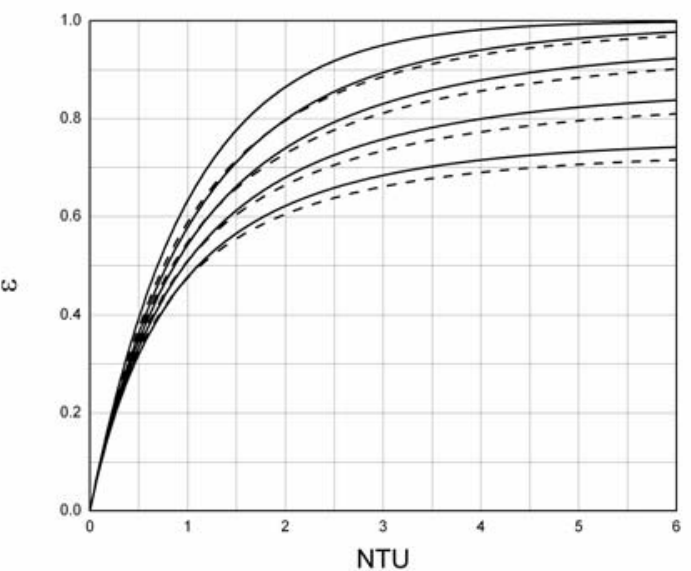

(b)

Figure 5: Effectiveness of the theoretical relation (dashed line) and the model prediction (straight line) of a staggered two-row and two-circuit cross-flow heat exchanger (geometry 2):

(a) $\mathrm{C}_{\max }$ (mixed), $\mathrm{C}_{\min }$ (unmixed); (b) $\mathrm{C}_{\min }$ (mixed), $\mathrm{C}_{\max }$ (unmixed).

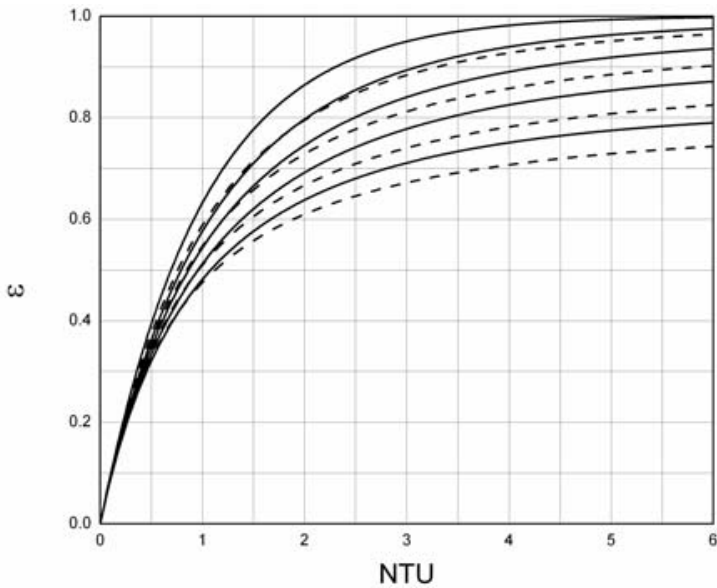

(a)

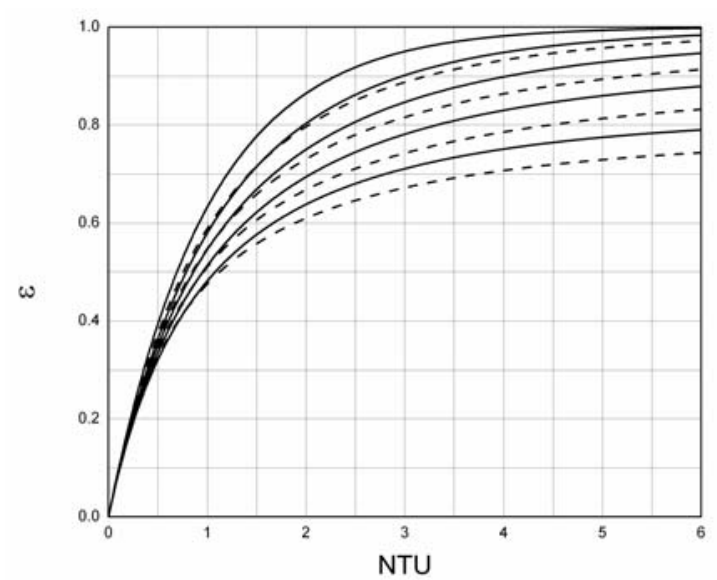

(b)

Figure 6: Effectiveness of the theoretical relation (dashed line) and the model prediction (straight line) of a staggered three-row and two-circuit cross-flow heat exchanger (geometry 3 ):

(a) $\mathrm{C}_{\max }$ (mixed), $\mathrm{C}_{\min }$ (unmixed); (b) $\mathrm{C}_{\min }$ (mixed), $\mathrm{C}_{\max }$ (unmixed). 


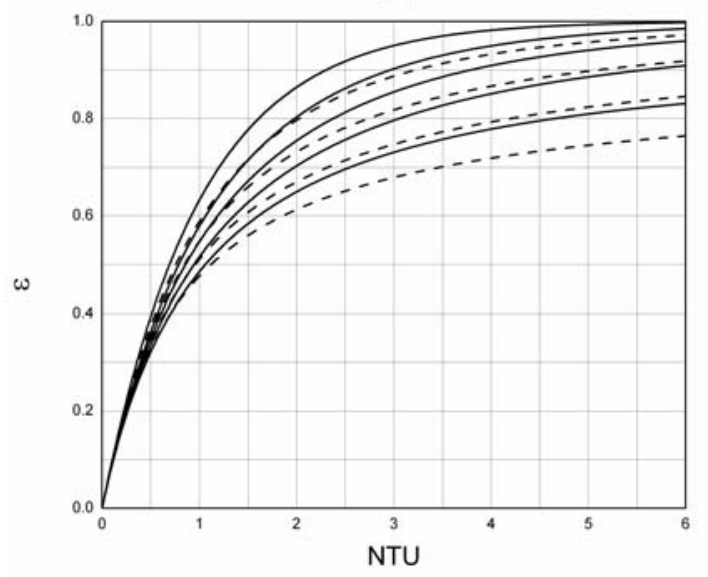

(a)

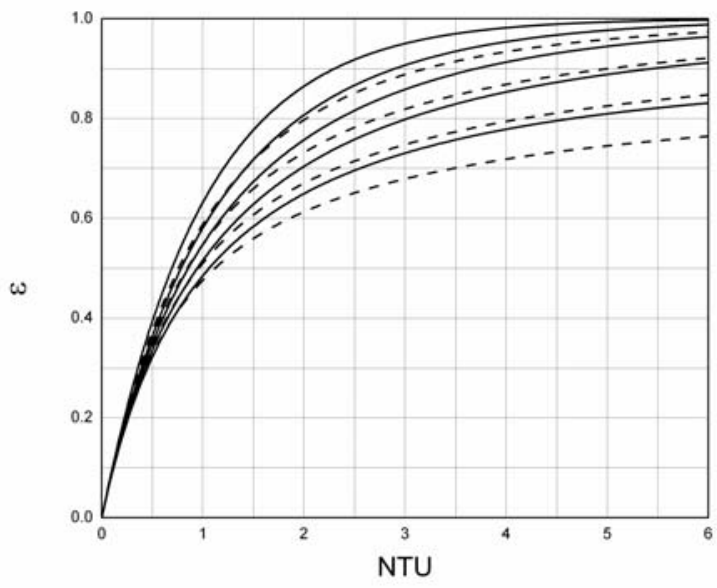

(b)

Figure 7: Effectiveness of the theoretical relation (dashed line) and the model (straight line) of a staggered six-row and five-circuit cross-flow heat exchanger (geometry 4):

(a) $\mathrm{C}_{\max }$ (mixed), $\mathrm{C}_{\min }$ (unmixed); (b) $\mathrm{C}_{\min }$ (mixed), $\mathrm{C}_{\max }$ (unmixed).

When there is no available relation for the effectiveness of a heat exchanger with a complex flow arrangement, an approximation using a theoretical relation for the same number of rows is used. In these cases, significant differences between real and computed values of theoretical effectiveness can occur. Figs 4 to 6 show a comparison between effectiveness values obtained from both theoretical relations (Eqs. 14-16) and computational results for geometries 1-3 (Fig 3a-c). Table 5 shows maximum and total errors obtained for each case. In Fig. 4 it can be seen that a theoretical relation always overestimates effectiveness values for geometry 1 up to a maximum error of about $12 \%$ (see Table 5), for both $\mathrm{C}_{\min }=\mathrm{C}_{\mathrm{air}}$ and $\mathrm{C}_{\min }=\mathrm{C}_{\text {fluid. }}$. In the cases of Figures 5 and 6 it can be observed that the theoretical relation underpredicts the effectiveness values for geometries 2 and 3, respectively, in almost the entire NTU range. The difference is more pronounced for geometry 3 up to approximately $6.3 \%$. In both of these graphs two different regions are observed, one where the theoretical effectiveness is greater and other where the simulated effectiveness is greater. The second region is more pronounced in Figures 5 and 6 , practically extending over all NTU values higher than two. This behavior depends on the kind of geometry that is simulated. For very small values of $\mathrm{C}^{*}$ the first region must be extended to higher NTU numbers.

Table 5: Average and maximum relative errors for geometries 1, 2, 3, and 4.

\begin{tabular}{|l|c|c|}
\hline \multirow{2}{*}{ Geometry } & \multicolumn{2}{|c|}{ Average relative error (\%), Maximum relative error (\%) } \\
\cline { 2 - 3 } & $\mathbf{C}_{\min }=\mathbf{C}_{\text {air }}$ & $\mathbf{C}_{\min }=\mathbf{C}_{\mathbf{t}}$ \\
\hline & $0 \leq \mathrm{NTU} \leq 6$ & $0 \leq \mathrm{NTU} \leq 6$ \\
model (geometry 1)- Eq.(15) & $6.40,12.02$ & $4.49,11.94$ \\
model (geometry 2)- Eq. (15) & $2.08,4.61$ & $2.14,4.52$ \\
model (geometry 3)- Eq. (16) & $3.12,6.29$ & $3.18,6.29$ \\
model (geometry 4)- & $3.93,8.72$ & $4.04,8.72$ \\
model (geometry t6) & $3.29,8.31$ & $3.45,8.40$ \\
model (geometry 4)- Eq.(18) & $3.67,7.81$ & $3.86,7.81$ \\
model (geometry 4)- Eq.(19) & & \\
\hline
\end{tabular}

Figure 7 shows a comparison between simulation results for geometry 4 and those for the geometry with six rows for the pure cross-flow heat exchanger, both obtained with the present computational program. The same tendency as that shown in Figures 5 and 6 for effectiveness values can be observed. In this case the maximum error was about $8.7 \%$. Comparisons between geometry 4 and the approximate infinite theoretical relation (Eq. 18), and geometry 4 and Eq. 19 are also illustrated in Table 5. In these cases the use of Eqs. (18) and (19) in the process of experimental data reduction also results in an erratic estimation of thermal effectiveness, because these relations are valid for a cross-flow heat exchanger with both fluids unmixed and an infinite number of tube rows. This condition is valid when 
almost 20 or more rows are considered (see Table 4). This criterion was used by Stevens et al. (1957) in their numerical simulations.

\section{CONCLUSIONS}

The present paper is an extension of Navarro and Cabezas-Gómez's (2005) previous work. Two new aspects were introduced, the first a more detailed explanation of the computational methodology and the second a presentation of new results for complex heat exchanger geometries for which $\varepsilon$-NTU relations are not available.

A simulation element-by-element model discretizes the whole heat exchanger into smaller ones along the tube fluid path based on a local effectiveness concept. Computing the temperature distribution of both fluids, the overall effectiveness of the heat exchanger is calculated. The model was validated through comparison with theoretical relations found in the literature, obtaining very small relative errors in all cases. The comparisons reveal that the model is accurate and suitable for predicting the theoretical performance of coils.

Effectiveness values were estimated for crossflow heat exchangers with complex flow arrangements. For the cases analyzed, a maximum difference of about $10 \%$ was noted between effectiveness model prediction and those based on theoretical formulae. This should be considered in experimental work. The results shown in Table 5 for more than four rows indicate that the use of Eq. (18) produces imprecise experimental values, which can results in an erroneous conclusion about the effect of the flow arrangement on a specific geometry. Finally, it must be said, that due to its prediction capability, the model developed is a useful research tool for theoretical and experimental studies on heat exchanger performance.

\section{NOMENCLATURE}

$\begin{array}{ll}\text { A } & \begin{array}{l}\text { exchanger total outer heat } \\ \text { transfer area }\end{array} \\ \mathrm{A}_{\mathrm{fr}} & \text { exchanger total frontal area] } \\ \mathrm{C} & \text { heat capacity rate } \\ \mathrm{C}^{*} & \mathrm{C}_{\min } / \mathrm{C}_{\max } \\ \mathrm{L} & \text { tube fluid flow length } \\ \mathrm{N}_{\mathrm{c}} & \text { number of circuits } \\ \mathrm{N}_{\mathrm{e}} & \text { number of elements per tube } \\ \mathrm{N}_{\mathrm{r}} & \text { number of rows } \\ \mathrm{N}_{\mathrm{t}} & \text { number of tubes per row }\end{array}$

$\begin{array}{llr}\text { NTU } & \text { number of transfer units [-] } & \\ \text { Q } & \text { heat transfer rate } & {[\mathrm{W}][\mathrm{K}]} \\ \mathrm{T} & \text { temperature } & \\ \mathrm{U} & \text { overall heat transfer } & {\left[\mathrm{W} /\left(\mathrm{m}^{2}-\mathrm{K}\right)\right]} \\ & \text { coefficient } & \end{array}$

\section{Greek Symbol}

$\delta \quad$ denotes difference $\quad(-)$

$\Delta \quad$ denotes difference $\quad(-)$

$\varepsilon \quad$ effectiveness of heat (-)

$\Gamma \quad$ dimensionless parameter defined by Eqs. (6) and (8).

\section{Subscripts}

C cold fluid side of heat (-)

$\mathrm{H}$ hot fluid side of heat (-)

I inlet conditions

max maximum value (-)

min minimum value (-)

$\mathrm{O} \quad$ outlet conditions (-)

\section{Superscripts}

e element

\section{REFERENCES}

Bansal, P.K. and Purkayastha, B., An NTU-e Model for Alternative Refrigerants, International Journal of Refrigeration, 21, No. 5, 381 (1998).

Bensafi, A., Borg, S., and Parent, D., CYRANO: A Computational Model for the Detailed Design of Plate-fin-and-tube Heat Exchangers Using Pure and Mixed Refrigerants, International Journal of Refrigeration, 20, No. 3, 218 (1997).

Corberán, J.M. and Melón, M.G., Modelling of Plate Finned Tube Evaporators and Condensers Working with R134a, International Journal of Refrigeration, 21, No. 4, 273 (1998).

Domanski, P.A., Simulation of an Evaporator with Non-uniform One-dimensional Air Distribution, ASHRAE Transactions, 97, No. 1, 793 (1991).

ESDU 86018, Effectiveness-NTU Relations for the Design and Performance Evaluation of Twostream Heat Exchangers, Engineering Science Data Unit 86018 with amendment, July, ESDU International plc, London, 92 (1991). 
Incropera, F.P. and DeWitt, D.P., Fundamentals of Heat and Mass Transfer, Four Ed., John Wiley \& Sons (1996).

Jang, J.-Y., Lai, J.-T., and Liu, L.-C., The Thermalhydraulic Characteristics of Staggered Circular Finned-tube Heat Exchangers under Dry and Dehumidifying Conditions, International Journal of Heat and Mass Transfer, 41, 3321 (1998).

Kays, W.M. and London, A.L., Compact Heat Exchangers, Third Ed., McGraw Hill, New York (1998).

Navarro, H.A. and Cabezas-Gomez, L., A New Approach for Thermal Performance Calculation of Cross-flow Heat Exchangers, International Journal Heat Mass Transfer, 48, 3880 (2005).

Rich, D.G., The Effect of the Number of Tube Rows on Heat Transfer Performance of Smooth Plate Fin-and-tube Heat Exchangers, ASHRAE Transactions, 308 (1973).

Stevens, R.A., Fernandez, J., and Woolf, J.R., Mean
Temperature Difference in One, Two and Threepass Crossflow Heat Exchangers, Transactions ASME, 79, 287 (1957).

Vardhan, A. and Dhar, P.L., A New Procedure for Performance Prediction of Air Conditioning Coils, International Journal of Refrigeration, 21, No. 1, 77 (1998).

Wang, C.-C., Lee, C.-J., Chang, C.-T., and Lin, S.P., Heat Transfer and Friction Correlation for Compact Louvered Fin-and-tube Heat Exchangers, International Journal of Heat and Mass Transfer, 42, 1945 (1999a).

Wang, C.-C., Tao, W.-H., and Chang, C.-J., An Investigation of the Airside Performance of the Slit Fin-and-tube Heat Exchangers, International Journal of Refrigeration, 22, 595 (1999b).

Wang, C.-C., Webb, R.L., and Chi, K.-Y., Data Reduction for Air-side Performance of Fin-andtube Heat Exchangers, Experimental Thermal and Fluid Science, 21, 218 (2000). 